\title{
Charter Schools and Mathematics Achievement in the State of Georgia
}

\author{
Dr. Raymond D. Mooring ${ }^{\text {ab }}$ (Corresponding author) \\ ${ }^{\text {a }}$ Analysis Made Easy \\ 1941 Boulder Gate Drive, Ellenwood, Georgia 30294, United States \\ Tel: 1-404-803-7585 E-mail: rmooring@analysismadeeasy.com \\ ${ }^{\mathrm{b}}$ Dept. of Educational Policy Studies, Georgia State University \\ 30 Pryor Street, Atlanta, Georgia 30302, United States \\ Tel: 1-404-803-7585 E-mail: rmooring@gsu.edu
}

Received: Jan. 4, 2017 Accepted: Feb. 8, $2017 \quad$ Published: February 8, 2017

doi:10.5296/jse.v7i1.10461 URL: http://dx.doi.org/10.5296/jse.v7i1.10461

\begin{abstract}
This study uses hierarchical linear modeling (HLM) and factorial analysis of covariance (ANCOVA) to investigate the relationship between a school's charter status and Math achievement. After accounting for school gender and ethnicity effects, charter school status is associated with Math achievement. Specifically, the initial status of Math achievement varies depending on ethnicity and gender, but the growth rate does not. Furthermore, district characteristics help to explain the charter school effect on Math achievement. Charter schools outperform traditional public schools when they receive an average amount of instructional funds. To this end, the charter gap in Math achievement decreases over time in districts that spend on instruction and have a substantial amount of minorities. When compared to traditional public schools with similar characteristics, charter schools with high percentages of Black students and/or low percentages of females outperformed their matched traditional public school counterparts.
\end{abstract}

Keywords: Charter Schools, Mathematics Achievement, CRCT, Hierarchical Linear Modeling, Factorial ANCOVA 


\section{Introduction}

Students in the United States have less Math proficiency than students in many industrial and developing countries including Vietnam, Latvia, the United Kingdom, Slovenia, and France. Indeed, US students have not fared very well on international (e.g. Program for International Student Assessment (PISA), Trends in International Mathematics and Science) or national assessments (e.g. National Assessment of Educational Progress (NAEP)). For example, only $36 \%$ of eighth graders were found to be "proficient" or "advanced" in Math on the NAEP (as cited by (Desilver, 2015)).

In 2013, the average score on the NAEP Mathematics assessments for eighth graders was 294 (out of 500) compared to an average of 272 and 263 for Hispanics and Blacks respectively (National Center for Education Statistics). If the US is to improve its standing in the international community, it must take decisive steps to decrease its minority-White Math achievement gaps.

In the Math 2013 NAEP, 16 states had Math scores (from public schools) significantly lower than the national average. Most of these states are in the Southeast United States (Tennessee, Arkansas, Louisiana, Mississippi, Alabama, Georgia, South Carolina, and Florida) which have substantial Black populations and in the Southwest US (California, Nevada, Arizona, New Mexico) which have substantial Hispanic populations (National Center for Education Statistics, 2014).

One way to improve the country's international standing is to improve the performance of its minority students. Charter schools may hold the key to increasing minority student performance. Indeed, if charter schools can decrease or eliminate the persistent Math achievement gap between minorities and White students, then the United States could improve its standing simply by funding and supporting charter schools to the greatest extent possible.

Do charter schools better prepare students to take Math standardized tests than traditional public schools? What factors help to predict a charter school's ability to increase Math scores? Is the Math achievement gap between minorities and Whites mitigated, reduced, or eliminated in charter schools in comparison to traditional public schools? Do certain students perform better in Math in charter schools than in other traditional schools? This study attempts to address these questions using data from Georgia, a state in the Southeast US that has a substantial percentage of minorities and has performed worse than the national average in Math on the NAEP in 2013.

\subsection{Charter Schools}

Charter schools are publicly funded independent schools established by teachers, parents, or community groups under the terms of a charter with a local or national authority. They operate with freedom from some of the regulations that are imposed upon district schools.

The literature is unclear regarding whether or not students in charter schools outperform students in conventional public schools. Studies have shown that charter school students 
outperform comparable students in conventional schools (e.g., Hoxby, 2004) while others suggest that they perform worse than students in conventional schools (e.g., Buddin \& Zimmer, 2005; Hanushek \& Rivkin, 2006). Still other investigations (e.g., Seyedbagheri, 2012) were unable to find any statistically significant difference between charter and traditional public school performance.

Complicating matters is the fact that charter schools are not homogeneous. There is evidence suggesting that the outcomes of start-up charter schools differ from conversion charter schools (those that were originally conventional public schools). For example, a study in California (Buddin \& Zimmer, 2005) showed that when compared to conventional public schools, conversion charter schools had a small positive effect (less than one point) on the reading portion on a standardized test and a small negative effect (less than one point) on the Math portion. On the other hand, startup charter schools scored five points lower than traditional schools on the reading portion and seven points lower on the Math portion. Differences may exist in disciplinary as well as academic outcomes (e.g.Imberman, 2011). Researchers (e.g. Buddin \& Zimmer, 2005) have also found that established charter schools perform differently than newer charter schools.

\subsection{Literature Gap}

While overall charter school effects are still up for debate, it appears as though they may be more beneficial for certain students than for others. For example, using data from over 1,200 of Georgia's public elementary schools from 2005-2008, Roch and Pitts (2012) concluded that charter schools are likely to have higher Math scores than regular public elementary schools when the ethnicity of the teachers at the school closely mirrors the ethnicity of the students at large at the school. Furthermore, the authors suggest that minority students do better when they are taught by instructors from the same background. Hoxby (2004) contends that charter schools may make the most difference in areas with large poor or minority populations. In her national study, the Math proficiency advantage (comparing charter schools with the schools that charter students would most likely have attended if the charter school did not exist) for charter schools in highly Hispanic areas was $4.1 \%$ compared to $2.1 \%$ for the typical charter school. While this advantage appears nationally, does it still exist in states with large minority populations?

\subsubsection{Outcome Variable}

In most studies, students' mean scores on standardized tests are used as outcome variables. However, this study contributes to the literature because it uses schools as the unit of analysis as opposed to students. In Georgia, eighth-grade students must pass the Criterion Reference Competency Test (CRCT) to pass to the ninth grade. Unlike other high stakes standardized tests like the SAT and GRE where percentile ranking can have a significant effect on college and graduate school admission decisions, the magnitude of the score that students earn on the CRCT is less important than just earning a passing score.

\subsubsection{Geography}

There appears to be a shortage of papers investigating charter school achievement in the 
southeastern United States. Published studies on charter school achievement can be found using data from Arkansas, Florida, Michigan, Ohio, Pennsylvania, Massachusetts, New Jersey, North Carolina, Texas, California, and Washington, DC. (e.g., Carr \& Ritter, 2007; Cho, Chudnofsky, Jian, Landes, \& Mortimer, 2013; Hanushek \& Rivkin, 2006; Hoxby, 2003; Imberman, 2011; Mills, 2013; Raymond, 2011; Sass, 2006; Teske, Schneider, Buckley, \& Clark, 2000)). Studies have also been done in large urban districts including New York City, Boston, Albany, Chicago, Cleveland, Denver, and Indianapolis (Hoxby, Murarka, \& Kang, 2009; Hoxby \& Rockoff, 2005).

The Center for Research on Education Outcomes' national studies use data from the southeast US (Georgia and Louisiana). However, there is a need for statewide analyses because national analyses are dominated by the states with the most students. Studies using data from students in the southeast region of the United States (e.g., South Carolina, Georgia, Alabama, Mississippi, and Louisiana) are generally missing from the literature. This study attempts to fill that void by using charter school data from the state of Georgia, a large southern state (159 counties) with a sizeable African-American population (31\%) (United States Census Bureau, 2010), rural, urban, and suburban regions, pockets of affluence along with regions of poverty. Unlike in many other states, charter schools in Georgia are dispersed throughout the state and not just in urban areas.

\subsubsection{Statistical Technique}

The Mathematics achievement gap between White and minority students is not new. However, most of the studies found in the literature around achievement gap are correlational and regression studies. Few studies take advantage of the longitudinal nature of performance data. Rather, data from consecutive years are concatenated to create a large data snapshot. Unfortunately, these studies have several limitations. For one, they are not able to take advantage of trends in achievement over time. In the context of charter schools, the need to investigate trending becomes imperative since the literature suggests that newly created charter schools perform differently than established schools (Buddin \& Zimmer, 2005). As a consequence, it becomes important to track the within school variability of student achievement in addition to summary snapshot statistics like the mean pass rate. Second, their handling of missing data is sub-optimal. The common method of dropping cases that have incomplete data can bias the sample and weaken precision while imputing values may negatively bias standard error estimates. Hierarchical Linear Modeling (HLM) can handle this missing data problem without incurring many of the consequences of dropping, imputing, or deleting data.

Moreover, regression analysis does not take advantage of the hierarchical structure of achievement data. Schools are nested within districts and districts are nested within the state. Because of this, schools are more likely to be similar to other schools in their district than schools outside of their district. By clustering schools within districts, between-group differences can be analyzed and interpreted. Only HLM can address both within-group and between-group differences simultaneously while appropriately handling missing data. Using the results of a two-level HLM, Braun, Jenkins, and Grigg (2006) found that after adjusting 
for differences in student and school characteristics, the gap of the estimated average difference between Mathematics scores on the NAEP between charter schools and public non-charter schools is reduced by 2.5 points. However, when the scores were adjusted for state means, the gap closed by 0.6 points. To the author's knowledge, there are no published studies that use district-level characteristics along with student-level characteristics in an HLM to study charter schools' effects on the Math achievement gap of specific student populations. This current study fills this void.

\section{Goals and Objectives}

The primary goal of this study is to determine the effectiveness of Georgia's charter schools in preparing students to pass the Mathematics portion of the Criterion Reference Competency Test (CRCT). The second goal is to determine if Georgia's charter schools outperform non-charter schools in preparing students for the Math portion of the CRCT. The last goal is to determine if charter schools are more effective in preparing specific types of students to pass the CRCT exam than other students.

\section{Methodology}

Hierarchical linear modeling (HLM) is a statistical technique that allows researchers to develop and analyze growth models. These growth models are used to investigate individual change. As Raudenbush and Bryk (2002) explain, when HLM is "applied with valid measurements from a multiple-time-point design, these models afford an integrated approach for studying the structure and predictors of individual growth." HLM allows separate models to be developed for the initial status and growth rate of the phenomenon being studied. To this end, the growth rate model is closely associated with the slope of a typical regression. In addition, potential predictors at higher levels can be included in the models to predict either the initial status or the growth rate.

HLM allows for the partitioning of variance and covariance among levels and facilitates the investigation of cross-level effects. As a result, the relationship between district characteristics (like expenditure) and charter school's influence on Math achievement can be determined. In addition, HLM will allow an estimate of within-school, between-school, and between-district variation of Math achievement to be developed (Raudenbush \& Bryk, 2002). Finally, HLM allows for both random and fixed effects. This feature is important for situations where Level 1 slopes are conceived as varying randomly over the population of Level 2 units.

For this study, a suite of three-level hierarchical models was developed to investigate the research questions. In each model, the first level comprises the school growth trajectories in the percentage of students passing the Math portion of the CRCT exam. Level 2 investigates the variation in growth parameters among schools within the same district. Level 3 investigates the variation among districts. For each model, the outcome variable, $\mathrm{MATH}_{\mathrm{tij}}$ is the percentage of students in school $\mathrm{i}$ in district $\mathrm{j}$ that passed the Math portion of the CRCT state-wide exam in year $t$. 


\section{Data}

The data for this study is publicly available. Excel spreadsheets containing the data were downloaded in June 2015 from two Georgia state websites: the Georgia Department of Education website and The Governor's Office of Student Achievement website.

\subsection{Dependent Variable}

The primary unit of analysis for this hierarchical study is the school (rather than the student). The dependent variable used in this study is the percent of students meeting or exceeding the target on the Mathematics CRCT test. The Math portion of the CRCT was designed to assess how well students acquired the knowledge and skills described in the Quality Core Curriculum, Georgia's Standard (QCCGS). Five years' worth of data (2010-2014) integrated across all Georgia schools were used in the study (Georgia Department of Education, 2015a).

The dependent variable (labeled "MATH") is a function of year (t), school (i), and district (j) and ranges from 0 and 100 . So, for example, $\mathrm{MATH}_{\mathrm{tij}}=65$ implies that in year $\mathrm{t}, 65 \%$ of the students taking the Math CRCT in school $i$, located in district $\mathrm{j}$ met or exceeded the pre-specified target.

\subsection{Level 1 Predictors}

Since the primary unit of analysis is the school, the first level of data concerns itself with within-school variability. This is not the primary focus of this study of eighth grade CRCT scores. As a result, the only Level 1 predictor that was used in this study is time. The time variable (denoted YR) is the year that the exam was administered. It is centered on year 2012. Since data was obtained for a five year time span (2010-2014), valid values for this variable range from -2 to 2 .

\subsection{Level 2 and Level 3 Predictors}

Four Level 2 predictors (PCT_BLACK, PCT_HISPANIC, PCT_FEMALE, and CHARTER) and two Level 3 predictors (MINORITY and INSTRUCT) were used in the various HLM models. See Table 1 for details on the description and calculation of each predictor. 


\section{1) Macrothink}

Table 1. Descriptions of the predictors used in the various Hierarchical Linear Models

\begin{tabular}{|c|c|c|c|c|}
\hline Level & Predictor & Description & Valid Values & \\
\hline \multirow[t]{7}{*}{ Level 2} & PCT_BLACK & Percent of Black students in school & {$[0,1]$} & \\
\hline & PCT_HISPANIC & $\begin{array}{l}\text { Percent of Hispanic students in } \\
\text { school }\end{array}$ & {$[0,1]$} & \\
\hline & PCT_FEMALE & $\begin{array}{l}\text { Percent of Female students in } \\
\text { school }\end{array}$ & {$[0,1]$} & \\
\hline & CHARTER $^{+}$ & Charter school indicator & $\begin{array}{l}1=\text { charter } \\
0=\text { not a charter }\end{array}$ & \\
\hline & CHARTER-BLACK & $\begin{array}{l}\text { Interaction between charter school } \\
\text { indicator and percent of Black } \\
\text { students }\end{array}$ & $\begin{array}{l}\text { CHARTER } \\
\text { PCT_BLACK } \\
{[0,1]}\end{array}$ & $\mathrm{X}$ \\
\hline & CHARTER-HISPANIC & $\begin{array}{l}\text { Interaction between charter school } \\
\text { indicator and percent of Hispanic } \\
\text { students }\end{array}$ & $\begin{array}{l}\text { CHARTER } \\
\text { PCT_HISPANIC } \\
{[0,1]}\end{array}$ & $\mathrm{X}$ \\
\hline & CHARTER-FEMALE & $\begin{array}{l}\text { Interaction between charter school } \\
\text { indicator and percent of Female } \\
\text { students }\end{array}$ & $\begin{array}{l}\text { CHARTER } \\
\text { PCT_FEMALE } \\
{[0,1]}\end{array}$ & $\mathrm{X}$ \\
\hline \multirow[t]{2}{*}{ Level 3} & PCT_MINORITY & $\begin{array}{l}\text { Percent of minority students in a } \\
\text { district }\end{array}$ & {$[0,1]$} & \\
\hline & INSTRUCT $^{\wedge}$ & $\begin{array}{l}\text { Ratio of monies spent on } \\
\text { instruction and instruction support } \\
\text { to the number of students enrolled } \\
\text { (in US Dollars) }\end{array}$ & {$[0,10000]$} & \\
\hline
\end{tabular}

+ New charter schools, conversion charter schools (formerly non-charter public schools), and renewal charter schools (initial charter has expired) are all coded one.

${ }^{\wedge}$ Does not include monies spent on maintenance and operations, debt services, general administration, media, pupil services, motivation and capital projects, school administration, school food services, or transportation.

\section{Models}

The first model developed was a fully unconditional model (hereafter referred to as M0). This model does not contain any predictors at any of three levels.

$$
\mathrm{MATH}_{\mathrm{tij}}=\gamma_{000}+\mathrm{r}_{\mathrm{ij}}+\mu_{00 \mathrm{j}}+\mathrm{e}_{\mathrm{ti}}
$$

M0 was developed to ensure that there is a significant amount of within-school, between-school, and between-district variation to justify the inclusion of Level 2 and/or Level 3 predictors.

The remaining models are variations of the general three-level HLM where $p$ and $q$ are the number of level 1 and 2 predictors respectively, $\pi, \beta$, and $\gamma$ are the level 1 , level 2 , and level 3 coefficients respectively, $\mathrm{X}_{\mathrm{qij}}$ and $\mathrm{W}_{\mathrm{sj}}$ are level 2 and level 3 predictors respectively, $\mathrm{e}_{\mathrm{tij}}$ is the 


\section{Ml Macrothink}

level 1 random effect, and $r_{p i j}$ and $\mu_{p q j}$ are the unique level 2 and level 3 effects respectively (Equations 2-4). The model for the initial status of Math achievement term is identified when $p$ equals zero. The growth model is identified when $\mathrm{p}$ equals one.

$$
\begin{aligned}
& \text { Level 1: } M_{A T H} H_{\mathrm{tij}}=\pi_{0 \mathrm{ij}}+\pi_{1 \mathrm{ij}} \times Y R_{\mathrm{tij}}+e_{\mathrm{tij}} \\
& \text { Level 2: } \pi_{\mathrm{pij}}=\beta_{\mathrm{p} 0 \mathrm{j}}+\sum_{q=1}^{Q_{p}} \beta_{\mathrm{pqj}} \times \mathrm{X}_{\mathrm{qij}}+\mathrm{r}_{\mathrm{pij}} \\
& \text { Level 3: } \beta_{\mathrm{pqj}}=\gamma_{\mathrm{pq} 0}+\sum_{s=1}^{S_{p q}} \gamma_{\mathrm{pqs}} \times W_{\mathrm{sj}}+\mu_{\mathrm{pqj}}
\end{aligned}
$$

Model M1 includes a school's charter status along with its percentage of Blacks, Hispanics, and females as Level 2 variables. It was developed to determine the effects of charter schools on Math performance after accounting for the ethnic and gender make-up of schools. Coefficients from this model were used to make some initial estimates of the effects of ethnicity, gender, and charter status on the initial value and growth rates of Math performance.

Model M2 includes predictors at Level 2 and Level 3. The Level 3 predictors were grand-mean centered so the values of $\beta_{00 \mathrm{j}}, \beta_{01 \mathrm{j}}, \beta_{10 \mathrm{j}}$, and $\beta_{11 \mathrm{j}}$ are valid for a district with an average percentage of minorities and spends an average amount per student on instruction. The Level 3 predictors are set to predict the influence of the charter-gap on the initial status and growth rate of Math performance. Model M3 was developed to determine if charter schools are more effective in instructing specific types of students than others. Because of the interaction terms with the CHARTER indicator, this model only uses input from charter schools. A significant coefficient would imply a differentiation between the preparation that charter schools provide Blacks vs. non-Blacks, Hispanics vs. non-Hispanics, and/or males vs. females. The specific predictors for Models M1-M3 are listed in Table 2.

Table 2. Coefficients of Selected Hierarchical Linear Models

\begin{tabular}{l|c|c|c|c|c|c}
\multicolumn{1}{c}{} & \multicolumn{2}{c}{ Model M1 } & \multicolumn{2}{c}{ Model M2 } & \multicolumn{2}{c}{ Model M3 } \\
\cline { 2 - 7 } & $\begin{array}{c}\text { Initial } \\
\text { Status }\end{array}$ & $\begin{array}{c}\text { Growth } \\
\text { Rate }\end{array}$ & $\begin{array}{c}\text { Initial } \\
\text { Status }\end{array}$ & $\begin{array}{c}\text { Growth } \\
\text { Rate }\end{array}$ & $\begin{array}{c}\text { Initial } \\
\text { Status }\end{array}$ & $\begin{array}{c}\text { Growth } \\
\text { Rate }\end{array}$ \\
\hline INTERCEPT & $\mu_{00}$ & $\mu_{10}$ & $\gamma_{000}$ & $\gamma_{100}$ & $\gamma_{000}$ & $\gamma_{100}$ \\
\hline BLACK & $\mu_{01}$ & $\mu_{11}$ & $\gamma_{010}$ & $\gamma_{110}$ & & \\
\hline HISPANIC & $\mu_{02}$ & $\mu_{12}$ & $\gamma_{020}$ & $\gamma_{120}$ & & \\
\hline FEMALE & $\mu_{03}$ & $\mu_{13}$ & $\gamma_{030}$ & $\gamma_{130}$ & & \\
\hline CHARTER & $\mu_{04}$ & $\mu_{14}$ & $\gamma_{040}$ & $\gamma_{140}$ & & \\
\hline MINORITY & & & $\gamma_{041}$ & $\gamma_{141}$ & & \\
\hline INSTRUCT & & & $\gamma_{042}$ & $\gamma_{142}$ & & \\
\hline CHARTER-FEMALE & & & & & $\gamma_{010}$ & $\gamma_{110}$ \\
\hline CHARTER-BLACK & & & & & $\gamma_{020}$ & $\gamma_{120}$ \\
\hline CHARTER-HISPANIC & & & & & $\gamma_{030}$ & $\gamma_{130}$ \\
\hline
\end{tabular}




\section{Results}

The final estimation of fixed effects and variance components for each model is available upon request from the author. The fully unconditional model (Model M0) shows that there is a fair amount of between school $\left({ }^{2}=6,773.85, \mathrm{df}=365, \mathrm{p}<.001\right)$ and between $\operatorname{district}\left({ }^{2}=\right.$ $268.92, \mathrm{df}=172, \mathrm{p}<.001)$ variability. These findings provide support for including Level 2 and Level 3 variables to account for some of this variability. There is also a significant portion of within school variance $(t=77.541, p<.001)$ which suggests that the initial status and growth rate of Math performance can be investigated with the inclusion of a time variable.

\subsection{Charter Schools Effect after Accounting for Gender and Ethnicity}

When additional Level 2 predictors are included in the model, the variance associated with the charter indicator variable becomes a residual variance after accounting for the variance that is explained by the added predictors. In Model M1, the variance associated with the CHARTER variable is the amount of variance in Math achievement associated with CHARTER after accounting for gender and ethnicity effects.

Non-charter schools made up completely of white males can initially expect to have about $24 \%$ of their students pass the Math portion of the CRCT. To this end, the ethnicity and gender make-up of Georgia's schools are associated with the initial status of Math performance. For every $10 \%$ increase in the percentage of Blacks in a school, the expected percentage of students passing the Math portion of the CRCT decreases by 2.52 percentage points $(p<.001)$ controlling for all other Level 2 variables. Similarly, a 10\% increase in the percentage of Hispanics at a school decreases the expected Math performance by 1.33 percentage points ( $\mathrm{p}$ $<.001$ ). On the other hand, a 10\% increase in the amount of females at a Georgia school is associated with a 13.06 percentage point increase in initial status.

Ironically, growth rates are not associated with ethnicity, gender, or charter status. On average, a non-charter school of white males can expect an additional 3.3\% of their students to pass the Math CRCT each year. This finding suggests that the charter status of Georgia schools has no effect on the growth rate of their students passing the Math CRCT each year. There is considerable variation remaining in both the initial status and growth rate of Math achievement. When considered by itself, a school's charter status explains just $4.7 \%$ of the variability in the initial status of Math performance and $9.35 \%$ of the variability in the growth rate of Math performance. However, in Model M1 which includes ethnicity, gender, and charter status indicators, $61.86 \%$ of the variance in initial status and $78.77 \%$ of the variability in the growth rate is explained. This suggests that while charter status is a significant predictor of performance in the Math CRCT (especially initial status), its effects are modest.

\subsection{Charter Effects after Accounting for Gender and Ethnicity and Adjusting for District-Level Predictors}

Model M1 showed that charter affiliation was associated with Math performance even after accounting for the effects of gender and ethnicity. In Model M2, which includes both Level 2 and Level 3 predictors, CHARTER is associated with Math performance, even after accounting for the various school and district characteristics. In this model, all Level 3 effects 
were fixed with the exception of the Level 3 effects associated with the charter indicator. Both MINORITY and INSTRUCT were negatively associated with the charter-gap on growth rate and MINORITY was associated with initial status as well. Note that the main findings of Model M1 were duplicated using the results of Model M2 suggesting the robustness of the findings throughout this report. Also in Model M2, most of the variation associated with the charter-gap of the growth rate has been captured.

6.3 Is there a difference in the effectiveness of charter schools to prepare students for the Math CRCT by either ethnicity or gender?

To answer this question, Model M3 was used since the effects of non-charter schools $($ CHARTER $=0)$ fall out of the regression equation. Charter schools affect Math CRCT performance through the initial status term $\quad 0 \mathrm{ij}$. Charter schools with substantial percentages of females initially tend to do better on the Math CRCT than schools with lower percentages of females. At a school without any Black or Hispanic students, for every $10 \%$ increase in the concentration of females, the percentage of students passing the Math CRCT is expected to increase by 2.9 percentage points $(010=29.01, \mathrm{p}=.004)$.

On the other hand, charter schools with larger percentages of Blacks initially perform worse on the Math CRCT than charters schools with lesser amounts of Blacks ( $020=-8.80, p$ $=.032$ ). At an all-male charter school with no Hispanic students, every $10 \%$ increase in its Black population corresponds to a 0.9 decrease in its expected initial status. The school's Hispanic population does not appear to be associated with Math performance ( $030=-30.21$, $\left.\mathrm{p}=.232 ; \quad{ }_{130}=0.26, \mathrm{p}=.934\right)$. Neither gender nor ethnicity predicts the growth rate in Math performance $(110=3.71, \mathrm{p}=.315 ; \quad 120=-2.95, \mathrm{p}=.237)$.

These findings suggest that a charter school's ability to improve on its Math CRCT pass rate over time is independent of its ethnic and gender make-up. Having said this, Model M3 predicts that schools with large percentages of females can expect to enjoy a higher initial pass rate than others while schools with high minority percentages tend to have lower starting pass rates.

6.4 Do certain students perform better in Math in charter schools than in other traditional schools?

To address this final set of research questions, a main effects factorial ANCOVA was developed. First, charter schools were separated from non-charter schools. Next, for each school, the percentage of Blacks, Hispanics, and females at the school was examined. The school was placed into one of three buckets for each variable: less than $30 \%, 30$ to $70 \%$, and $70 \%$ or more. Since this study shows that instructional expenditure is related to Math achievement, it is included as a covariate. The dependent variable for this ANCOVA is the mean Math CRCT pass rate. All potential comparisons were not examined and Tukey's Studentized Range Test was used to control for Type I experiment-wise error rate. Used in this study, Tukey provides a conservative estimate of the number of significant differences. Out of 15 potential comparisons for each variable, only three are of interest (High-Charter vs. High Non-charter, Medium-Charter vs. Medium Non-charter, and Low-Charter vs. Low 
Non-Charter) because they allow for the analysis of the charter school effect on the mean CRCT Math pass rate between schools with similar ethnic compositions while also controlling for the amount of money spent on instruction. Mean scores are reported (not adjusted means) because the adjusted scores were not estimable due to a lack of degrees of freedom.

The omnibus analysis of covariance (ANCOVA) model with three independent variables, one covariate, and percent of eighth graders passing the Math CRCT as the dependent variable is statistically significant $(\mathrm{F}(14,499)=18.33$, p-value $<0.0001)$. Thirty-four percent of the variance in the pass rates is accounted for by the independent variables and the covariate. The results of the ANCOVA confirm the importance of instruction expenditure in predicting Math CRCT scores (Wilk's $=0.990, \mathrm{~F}(1,499)=5.00$, $\mathrm{p}$-value $=0.0258$ ). There are differences in Math CRCT scores by ethnicity and gender even after accounting for the effects of instruction expenditures. The differences exist when analyzing the performance of Black students (Wilk's $=0.720, \mathrm{~F}(4,499)=48.43$, p-value $<0.0001)$, Hispanic students (Wilk's = $0.963, \mathrm{~F}(4,499)=4.85, \mathrm{p}$-value $=0.0008)$, and female students $($ Wilk's $=0.934, \mathrm{~F}(4,499)=$ 8.79 , p-value $<0.0001)$.

Of interest here is the comparison between charter and non-charter schools with similar demographics. The Math CRCT pass rate in charter schools with high percentages of Black students is on average 18 percentage points higher $(95 \% \mathrm{CI}: 7.27-29.21)$ than the pass rate of non-charter schools with high percentages of Black students. The pass rates of charter schools with a medium and low number of Black students were not statistically different from the pass rates of students in their counterpart non-charter schools.

The average Math CRCT pass rates of charter schools is not statistically different from their matched non-charter schools, regardless of their concentration of Hispanic students. This finding confirms our earlier finding that a school's Hispanic population does not appear to be associated with Math performance.

On the other hand, the Math CRCT pass rates of charter schools with low percentages of females is on average 45 points higher (95\% CI: 6.09 - 83.74) than the pass rates in non-charter schools with low percentages of females. This difference is statistically significant. Since the ANCOVA used just one year of data, this finding is most related to the initial status variable in the HLMs. The earlier HLM results show that charter schools with high percentages of females perform well on the Math CRCT test. The finding from this ANCOVA suggests that schools with considerable female representation perform well on the Math CRCT regardless of their charter status. The mean Math pass rate of charter and non-charter schools with high concentrations of females was $92.63 \%$ and $87.96 \%$ respectively. The pass rate for those charter and non-charter schools with medium concentrations of females was $81.19 \%$ and $80.92 \%$ respectively. It is interesting to note that females in these charter schools outperformed those in similar non-charter schools even though the differences were not statistically significant. 


\section{Discussion}

This study uses a series of hierarchical linear models to uncover the relationship between charter school status and Math achievement as measured by the eighth grade Math CRCT in Georgia. According to a model that includes just the charter status predictor (not shown), 75\% of students in non-charter schools and $77 \%$ of students in charter schools are predicted to pass the Math CRCT. On average, non-charter schools can expect their pass rate to increase by about two percentage points each year while charter schools can enjoy about a three percentage point increase in their pass rate. While it is encouraging that performance is increasing over time, neither the initial status difference nor the growth rate difference is statistically significant. This finding seems to support Seyedbagheri (2012) who was unable to find a significant difference between the academic performances of charter and public schools on the Math CRCT. However, Seyedbagheri (2012) used a series of dependent t-tests to address the research questions. Unfortunately, t-tests can only compare groups on mean values. No attempt is made to control for other potentially confounding variables that may be related to Math achievement (e.g., type of charter school). These results should be considered preliminary at best especially since the results of this study confound results from various types of charter schools including start-up, renewal, conversion, established, and new charter schools.

The charter status variable explains less than $5 \%$ of the variability in initial status and $9 \%$ of the variability in the growth rate. However, once gender and ethnicity indicators are added to the model, $62 \%$ and $79 \%$ of the variance in initial status and growth rates respectively are explained by charter status. This finding is at odds with the previous assertion that charter schools are unrelated to Math achievement. Indeed, after accounting for gender and ethnicity effects, charter status is a significant predictor of the initial status of Math achievement. However, its effects are modest.

The remaining results from this model are also worthy of mention. According to this model, the expected initial pass rate of schools with large populations of Black or Hispanic students is less than the initial pass rate of schools without this level of diversity. This finding provides support to the well-documented notions that Blacks and Hispanics tend to do worse on standardized testing than White students (Berrong, 2012; Camara \& Schmidt, 1999; Pettett, 2012). On the other hand, the model predicts that schools with high percentages of females will have a higher initial status than those with small percentages of females. This finding is also in line with Ryan and Ryan (2005) who report that females outperform males in Math during their childhood and adolescent years.

In addition to school level characteristics, district characteristics can provide some insight into the relationship between charter status and Math achievement. When just Level 3 predictors were investigated (model not shown), the district's minority percentage was positively associated with the charter-gap on initial status. That is, in districts with a large percentage of minority students, charter schools initially outperform non-charter schools in Math CRCT performance. This is encouraging because according to Hoxby (2004), "charter schools disproportionately arise where families are relatively poor, likely to be racial 
minorities, likely to speak English as a second language, and likely to have a single parent." Accordingly, charter schools improve achievement more when they operate in areas where families are more disadvantaged and are less able to choose their school (Hoxby, 2004).

The amount of expenditure spent on instruction and instructional activities is associated with the charter-gap on growth rate. Charter schools from districts that spend an average amount on student instruction and have an average percentage of minorities have a growth rate 2.3 percentage points higher than non-charter schools in the same district. After adjusting for a school's charter status, an increase in district minority concentration in a district that spends an average amount in instruction and an increase in the amount of money a district spends on instruction per student in a district that has an average amount of minorities both predict a decrease to the growth rate. These findings suggest that the charter gap in Math achievement decreases over time in districts that spend on instruction and have a substantial amount of minorities. These findings are contrary to the findings from van Beurden (2011). Using a series of Pearson correlations, van Beurden determined that instructional per pupil expenditures were not correlated with fifth grade CRCT Math achievement. However, correlations are not able to account for other district or school level characteristics simultaneously. Unlike partial correlations, the Pearson correlation coefficient ignores the effects of other variables. When the other variables are associated with Math achievement, the Pearson correlation will not be a reliable estimate of the association between the two variables.

Having said this, the effects found in this current study are pretty robust. In an analysis that included the charter status indicator, gender and ethnicity indicators for the school, minority percentage and instruction expenditure across the district, the charter status was still significantly associated with Math performance. In addition, the district level predictors both are negatively associated with the charter gap on growth rate and the minority variable is associated with the initial status as well. However, when both Level 2 and Level 3 predictors are included, the instruction expenditure variable positively predicted the initial status and growth rate of the charter-gap. In other words, after accounting for school and district characteristics, charter schools that receive the same amount of instructional resources as non-charter schools perform better than their non-charter counterparts initially. Moreover, this charter gap continues to increase over time. This finding appears to be in line with the Houck, Rolle, and He (2010) study that reports that performance in Georgia is linked to the percentage of expenditures dedicated to instruction. The authors found that while overall and special education spending decreases district efficiency, the percent of funding provided towards instruction is associated with increased efficiency and effectiveness of school districts. As explained in their paper, an efficient district is one which is able to generate higher than expected educational outcomes using lower than expected expenditures while an effective district is one that is able to generate higher than expected educational outcomes using higher than expected expenditures.

While it is beneficial to be able to determine that charter schools are indeed having an effect on Math performance throughout the state even after accounting for various school and district characteristics, this study's primary contribution to the literature is its ability to 
determine if charter schools are affecting some groups of students differently than other groups.

To investigate this, a model with three charter interactions (with Black, Hispanic, and female) was analyzed. The charter interactions affect Math performance primarily through the initial status of Math performance. Charter schools with few Black students tend to have higher initial Math achievement than charter schools with a large percentage of Black students. Charter schools with a large percentage of females initially perform better than charter schools with small percentages of females. However, initial Math achievement in charter schools does not appear to be associated with the school's percentage of Hispanic students. Neither ethnicity nor gender predicts the growth rate in Math performance. In other words, a charter school's ability to improve upon its pass rate over time is independent of its gender and ethnic make-up.

Since charter schools with high minority percentages tend to earn lower pass rates, there is substantial room for improvement. However, it may be the case that these high minority schools also contain a large percentage of low-income students. And as such, the effects of ethnicity and socioeconomic status may be conflated. According to the American Psychological Association's Presidential Task Force Report (2012), high minority, low-income schools have fewer resources, fewer credentialed teachers, higher student-teacher ratios, and larger class sizes. These factors may also contribute to the achievement gap. Since research exists that suggest the low-income students do not perform well on standardized tests (e.g., Sadker \& Zittleman, 2004; Veny, 2013), it would be informative to conduct a similar study that attempts to model Math achievement using charter status, the proportion of Black students in the school, and percent of low-income students in the school as predictors. Such a model could empirically separate the effects of the low-income variable from the ethnicity variable.

In summary, this study shows that charter status is associated with Math achievement primarily through its initial status. Even though Blacks and Hispanics underperform in comparison to their White counterparts, females at this age tend to outperform their male counterparts in both charter and non-charter schools initially. While initial variations exist, there does not appear to be much of a link between ethnicity and the growth rate of Math achievement over time.

The most robust linkage to Math achievement does not appear at the school level but at the district level. The amount of money a district spends on instruction is linked to both the initial status and growth rate of Math achievement. Specifically, the charter gap in Math achievement decreases over time in districts that spend on instruction and have a substantial amount of minorities. In addition, charter schools outperform their non-charter school counterparts when they receive an average amount of instructional funds from their district. This finding seems to contradict the James, et al. (2011) study which determined that instruction expenditures did not have a significant effect on eighth grade Math CRCT scores in Georgia. However, unlike this study which accounted for district and school effects, the James's study did not account for any community, school, leader, or teacher effects. The 
current study's findings do corroborate with Houck, et al. (2010) who found that in an analysis including various district characteristics, only the percent of funding provided towards instruction is associated with increased efficiency and effectiveness of school districts. They also support Hoxby (2004) who contends that charter schools perform better when their funding is at least $40 \%$ of the funding of regular public schools in the state.

Taken together, all of these results suggest that one of the most efficient ways of supporting charter schools situated in low-income and/or high minority communities is beyond their control. These schools have lower initial scores than their counterparts but a substantial investment in the instruction of their students promises to be a very effective method of reducing the Math achievement charter-gap over time. The utility of charter schools is already evident: charter schools with high percentages of Black students and low percentages of females perform better on the Math CRCT than their matched traditional public schools.

\section{Limitations}

While this study makes a significant contribution to our understanding of charter schools' effects on Math achievement, there are some limitations with the study's design. In this study, no distinction was made between start-up and conversion charters. Previous literature has shown that the two types of charter schools do not have the same effects on either standardized testing in general or Math achievement specifically. For example, using data from a large urban school district in the Southwest, Imberman (2011) found that conversion charter schools have little impact on cognitive and non-cognitive skill formation. On the other hand, start-up charters were found to improve Math test scores in middle schools.

Researchers have also found that charters who have been in existence longer tend to have different outcomes than newly formed charters. For example, Buddin and Zimmer (2005) found that students in new charter schools do significantly worse than other public school students while students in charter schools at least two years old do as well as conventional public school students. Unfortunately, the length of time that the charter school has been in existence was not captured or analyzed in the current study.

Because the current study combines various types of charters that have been in existence for a short, medium, and relatively long time, this study may suffer from aggregation bias. As such, the results reported in the study involving the charter variable may be considered conservative estimates of the true results though previous research suggests that the heterogeneity in charter schools' performance is independent of their length of operation (Hanushek \& Rivkin, 2006). Even though Slovacek, Kunnan, \& Kim (2002) found that California's low- income charter schools' student achievement was improving at a faster rate than in similar non-charter schools, this study was unable to link the growth rate of a school's Math achievement to its charter status.

In addition, the results of this study may not generalize to other contexts. This study used data from all school districts and schools in the state of Georgia. Therefore, the data used in this study can be thought of as a census of all Georgia schools (and not a random sample). Since generalizability typically follows randomization, it is quite possible that the results here are 
only appropriate for Georgia schools and/or may only generalize to other states that have similar demographics and educational structures as Georgia.

To be sure, caution would be advised before generalizing the results to other states. Standardized tests have specific (and sometimes different) objectives and may test different content using different question formats. As such, a student who may excel in the CRCT may struggle in other standardized tests. Before generalizing, researchers should account for this additional outcome-specific variance. Unfortunately, the magnitude of this variance is unknown for most students because students usually do not take both types of standardized tests.

Finally, the results of this study may not generalize to Georgia schools going forward. After the 2013-2014 summer retest, Georgia retired the CRCT and replaced it with the Georgia Milestones test. Beginning in 2014-2015, as part of the Georgia Milestones, Georgia students in grades 3 through 8 took an end-of-grade assessment in English Language Arts and Mathematics while students in grades 5 through 8 also took a science and social studies assessment. High school students in the state are required to take ten end-of-course assessments in areas designated by the State Board of Education (Georgia Department of Education, 2015b). The Milestones test measures how well students have learned the knowledge and skills outlined in the state-adopted content standards in language arts, Mathematics, science, and social studies. Unlike the CRCT which was specifically intended to test Georgia's performance/content standards outlined in the CCGPS/GPS, the Georgia Milestones test includes norm-referenced items in all content areas and courses that will provide a national comparison. Initial results suggest subtle differences in the tests. In 2014, $81.5 \%$ of Georgia's eighth graders met or exceeded $(47.5 \%$ met, $34.1 \%$ exceeded) the Mathematics CRCT standard. Statewide, in spring 2015, only $36.9 \%$ of eighth graders who took the Milestones were classified as proficient (24.8\%) or distinguished learners $(12.1 \%)$ in Mathematics. This large discrepancy may affect the interpretation of any analysis which includes data from both the CRCT and Georgia Milestones.

\section{Acknowledgement and Sponsoring Information}

The author acknowledges Suzanne De Haney for providing insightful comments that helped to improve upon an earlier version of this manuscript. This research did not receive any specific grant from funding agencies in the public, commercial, or not-for-profit sectors.

\section{References}

American Psychological Association. (2012). Ethnic and racial disparities in education: Psychology's contributions to understanding and reducing disparities. In: Washington, DC: American Psychological Association, Presidential Task Force on Educational Disparities. Retrieved from http://www.apa.org/ed/resources/racial-disparities.pdf.

Berrong, D. A. (2012). The relationship between principal turnover and student achievement in reading/english language arts and Math grades six through eight. (Doctoral dissertation, Liberty University). 
Braun, H., Jenkins, F., \& Grigg, W. (2006). A Closer Look at Charter Schools Using Hierarchical Linear Modeling. NCES 2006-460. National Center for Education Statistics.

Buddin, R., \& Zimmer, R. (2005). Student achievement in charter schools: A complex picture. Journal of Policy Analysis and Management, 24, 351-371. https://doi.org/10.1002/pam.20093

Camara, W. J., \& Schmidt, A. E. (1999). Group differences in standardized testing and social stratification: College Entrance Examination Baord.

Carr, M., \& Ritter, G. (2007). Measuring the competitive effect of charter schools on student achievement in Ohio's traditional public schools. National Center for the Study of Privatization in Education (Columbia University) Research Paper, 146.

Cho, E., Chudnofsky, A., Jian, Y., Landes, M., \& Mortimer, L. (2013). The Impact of Charter Schools on Traditional Public School Finances and Demographics. Durham, NC: Duke University.

Desilver, D. (2015). US students improving - slowly - in Math and science, but still lagging internationally. In (Vol. 2015): Pew Research Center.

Georgia Department of Education. (2015a). CRCT Statewide Scores. In (Vol. 2015).

Georgia Department of Education. (2015b). Georgia Milestones Assessment System. In (Vol. 2015).

Hanushek, E. A., \& Rivkin, S. G. (2006). School quality and the black-white achievement gap: National Bureau of Economic Research. https://doi.org/10.3386/w12651

Houck, E. A., Rolle, R. A., \& He, J. (2010). Examining school district efficiency in Georgia. Journal of Education Finance, 35, 331-357. https://doi.org/10.1353/jef.0.0022

Hoxby, C. M. (2003). School choice and school productivity. Could school choice be a tide that lifts all boats? In The economics of school choice (pp. 287-342): University of Chicago Press. https://doi.org/10.7208/chicago/9780226355344.001.0001

Hoxby, C. M. (2004). Achievement in charter schools and regular public schools in the United States: Understanding the differences: Harvard University.

Hoxby, C. M., Murarka, S., \& Kang, J. (2009). How New York City's charter schools affect achievement. Cambridge, MA: New York City Charter Schools Evaluation Project, 1-85.

Hoxby, C. M., \& Rockoff, J. E. (2005). Findings from the city of big shoulders. Education Next, 5.

Imberman, S. A. (2011). Achievement and behavior in charter schools: Drawing a more complete picture. The Review of Economics and Statistics, 93, 416-435. https://doi.org/10.1162/REST_a_00077

James, L., Pate, J., Leech, D., Martin, E., Brockmeier, L., \& Dees, E. (2011). Resource Allocation Patterns and Student Achievement. International Journal of Educational Leadership Preparation, 6, n4. 
Mills, J. N. (2013). The achievement impacts of Arkansas open-enrollment charter schools. Journal of Education Finance, 38, 320-342.

National Center for Education Statistics. Mobile Digest of Education Statistics, 2013.

National Center for Education Statistics. (2014). A First Look: 2013 Mathematics and Reading: NATIONAL ASSESSMENT OF EDUCATIONAL PROGRESS AT GRADES 4 AND 8. In. Washington, DC.

Pettett, W. R. (2012). The impact of the No Child Left Behind Act and school choice on student achievement: THE UNIVERSITY OF SOUTHERN MISSISSIPPI.

Raudenbush, S. W., \& Bryk, A. S. (2002). Hierarchical linear models: Applications and data analysis methods (Vol. 1): Sage.

Raymond, M. (2011). Charter School Performance in Pennsylvania. In: Stanford, CA: Center for Research on Education Outcomes, Stanford University.

Roch, C. H., \& Pitts, D. W. (2012). Differing effects of representative bureaucracy in charter schools and traditional public schools. The American Review of Public Administration, 42, 282-302. https://doi.org/10.1177/0275074011400404

Ryan, K. E., \& Ryan, A. M. (2005). Psychological processes underlying stereotype threat and standardized Math test performance. Educational Psychologist, 40, 53-63. https://doi.org/10.1207/s15326985ep4001_4

Sadker, D., \& Zittleman, K. (2004). Test Anxiety: Are Students Failing Tests-Or Are Tests Failing Students? Phi Delta Kappan, 85, 740-751. https://doi.org/10.1177/003172170408501007

Sass, T. R. (2006). Charter schools and student achievement in Florida. Education, 1, 91-122. https://doi.org/10.1162/edfp.2006.1.1.91

Seyedbagheri, T. (2012). Academic achievement of Georgia charter schools compared to traditional public schools: Implication for policy: Lincoln Memorial University.

Slovacek, S. P., Kunnan, A. J., \& Kim, H.-J. (2002). California Charter Schools Serving Low-SES Students: An Analysis of the Academic Performance Index.

Teske, P., Schneider, M., Buckley, J., \& Clark, S. (2000). Does Charter School Competition Improve Traditional Public Schools? Civic Report.

United States Census Bureau. Profile of General Population and Housing Characteristics: 2010 In American FactFinder.

van Beurden, K. (2011). Per Pupil Expenditures and Academic Achievement in Georgia School Systems. PIEDMONT COLLEGE.

Veny, V. (2013). The No Child Left Behind Act: An Analysis of its Impact on the Academic Success of Students in Cobb and Fulton Counties in Georgia. 


\section{Copyright Disclaimer}

Copyright for this article is retained by the author(s), with first publication rights granted to the journal.

This is an open-access article distributed under the terms and conditions of the Creative Commons Attribution license (http://creativecommons.org/licenses/by/3.0/). 